\title{
Postnatal Differentiation of Basket Cells from Slow to Fast Signaling Devices
}

\author{
Daniel Doischer, ${ }^{1 *}$ Jonas Aurel Hosp, ${ }^{1 *}$ Yuchio Yanagawa, ${ }^{3}$ Kunihiko Obata, ${ }^{4}$ Peter Jonas, ${ }^{1}$ Imre Vida, ${ }^{2,5}$ and \\ Marlene Bartos ${ }^{1,6}$ \\ ${ }^{1}$ Physiologisches Institut I and 2Institut für Anatomie und Zellbiologie I, Universität Freiburg, D-79104 Freiburg, Germany, ${ }^{3}$ Department of Genetic and \\ Behavioral Neuroscience, Gunma University, 371-8511 Maebashi, Gunma, Japan, ${ }^{4}$ Laboratory of Neurochemistry, National Institute for Physiological \\ Sciences, 444-8585 Myodaiji, Okazaki, Japan, ${ }^{5}$ Division of Neuroscience and Biomedical Systems, Faculty of Biological Sciences, University of Glasgow, \\ Glasgow G12 8QQ, United Kingdom, and 'Institute of Medical Sciences, University of Aberdeen, Foresterhill, Aberdeen AB25 2ZD, United Kingdom
}

Gamma frequency $(30-100 \mathrm{~Hz})$ oscillations in the mature cortex underlie higher cognitive functions. Fast signaling in GABAergic interneuron networks plays a key role in the generation of these oscillations. During development of the rodent brain, gamma activity appears at the end of the first postnatal week, but frequency and synchrony reach adult levels only by the fourth week. However, the mechanisms underlying the maturation of gamma activity are unclear. Here we demonstrate that hippocampal basket cells (BCs), the proposed cellular substrate of gamma oscillations, undergo marked changes in their morphological, intrinsic, and synaptic properties between postnatal day $6(\mathrm{P} 6)$ and $\mathrm{P} 25$. During maturation, action potential duration, propagation time, duration of the release period, and decay time constant of IPSCs decreases by $\sim 30-60 \%$. Thus, postnatal development converts BCs from slow into fast signaling devices. Computational analysis reveals that $\mathrm{BC}$ networks with young intrinsic and synaptic properties as well as reduced connectivity generate oscillations with moderate coherence in the lower gamma frequency range. In contrast, $\mathrm{BC}$ networks with mature properties and increased connectivity generate highly coherent activity in the upper gamma frequency band. Thus, late postnatal maturation of BCs enhances coherence in neuronal networks and will thereby contribute to the development of cognitive brain functions.

Key words: GABAergic neuron; development; dentate gyrus; basket cell; gamma; network

\section{Introduction}

Fast rhythmic network activity patterns in the gamma frequency band $(30-100 \mathrm{~Hz})$ are thought to be critically important for higher brain functions. Gamma oscillations have been proposed to represent reference signals for temporal encoding of information, sensory binding of features into a coherent percept, and storage and recall of information (Gray and Singer, 1989; Ribary et al., 1991; Buzsáki, 2006). In the hippocampus, amplitude and frequency of gamma oscillations change markedly during postnatal maturation (Lahtinen et al., 2002; Leinekugel et al., 2002). In rodents, gamma oscillations are first detected between postnatal day 6 (P6) and P10, and both coherence and frequency increase to reach adult levels at the fourth postnatal week (Lahtinen et al., 2002; Leinekugel et al., 2002). It is believed that these changes underlie the maturation of higher cognitive functions

\footnotetext{
Received June 23, 2008; revised Sept. 28, 2008; accepted 0ct. 16, 2008.

This work was supported by the Deutsche Forschungsgemeinschaft (SFB 505/C6, SFB 780/A5), the Bundesministerium für Bildung und Forschung (0I GQ 0420), the Volkswagenstiftung (I/78563-564), the Royal Society (M.B.) and by Grants-in-Aid for Scientific Research from Ministry of Education, Culture, Sports, Science, and Technology of Japan (Y.Y.). We thank W. Wisden for critically reading this manuscript. We thank J. Sauer for the quantification of GAD67/GFP-labeled cells in the dentate gyrus. We also thank K. Winterhalter, S. Becherer, M. Northemann, and U. Nöller for technical assistance.

${ }^{*}$ D.D. and J.A.H. contributed equally to this work.

Corresponding should be addressed to Dr. Marlene Bartos, Institute of Medical Sciences, University of Aberdeen, Foresterhill, Aberdeen AB25 2ZD,UK. E-mail: m.bartos@abdn.ac.uk.

D0I:10.1523/JNEUROSCI.2890-08.2008

Copyright $\odot 2008$ Society for Neuroscience $\quad$ 0270-6474/08/2812956-13\$15.00/0
}

both in rodents and humans (Ben-Ari et al., 2007; YurgelunTodd, 2007). However, the mechanisms involved in the maturation process of gamma activity in neuronal networks are insufficiently understood.

Networks of GABAergic interneurons play a key role in the generation of gamma oscillations. Among the various types of GABAergic cells (Buhl et al., 1994; Freund and Buzsáki, 1996; Miles et al., 1996; Parra et al., 1998; McBain and Fisahn, 2001; Somogyi and Klausberger, 2005), fast-spiking parvalbumin (PV)-expressing basket cells (BCs) are thought to be particularly important for network function (for review, see Bartos et al., 2007). Previous studies suggested that the fast signaling properties of BCs are necessary to optimize synchronization and to provide frequency tuning of network oscillations to the gamma band (Bartos et al., 2001, 2002; Galarreta and Hestrin, 2001; Buzsáki and Draguhn, 2004; Vida et al., 2006; Fuchs et al., 2007). The key role of $\mathrm{BCs}$ in the generation of gamma activity raises the intriguing possibility that developmental changes in functional properties and connectivity of BC-BC synapses are directly related to alterations in power and frequency of gamma oscillations. Consistent with this idea, during development the abundance of perisomatic inhibitory synapses increases (Tyzio et al., 1999), and the time course of miniature IPSCs in hippocampal principal cells becomes faster (Hollrigel and Soltesz, 1997; Cohen et al., 2000). Both factors will have a strong influence on the coherence and frequency of gamma activity (Traub et al., 1996; Wang and 
Buzsáki, 1996; Bartos et al., 2001, 2002). However, a systematic analysis of functional properties of BC-BC synapses in different phases of postnatal development has not been performed.

In the present study, we investigated the maturation of intrinsic and synaptic characteristics of BCs in the dentate gyrus of glutamate decarboxylase 67-green fluorescent protein (GAD67GFP)-expressing mice between the first and the fourth postnatal week by applying a combined neuroanatomical, electrophysiological, and computational strategy. We find that intrinsic and synaptic differentiation converts BCs from slow to fast signaling devices at multiple levels of cellular function. Increased axonal conduction velocity, faster kinetics of unitary IPSCs at BC output synapses, and higher connectivity in the network will support the developmental increase in coherence and frequency of gamma oscillations observed in vivo (Lahtinen et al., 2002).

\section{Materials and Methods}

Patch-clamp recording from $B C$. To identify interneurons at early developmental stages, heterozygous GAD67-GFP $(\Delta$ neo) mice expressing GFP under the control of the endogenous GAD67 gene promoter were used (Tamamaki et al., 2003). Transgenic mice were crossed with wildtype mice (C57BL/6), and GFP expression in the offspring was monitored by illuminating the heads with UV light $(<400 \mathrm{~nm})$. Transverse hippocampal slices (300 $\mu \mathrm{m}$ thickness) were cut from brains of 6- to 25-day-old mice using a Vibratome (DTK-1000; Dosaka; or a homemade slicer). Animals were killed by decapitation, in accordance with national and institutional guidelines. Patch pipettes were pulled from borosilicate glass tubing (outer diameter, $2 \mathrm{~mm}$; inner diameter, $1 \mathrm{~mm}$ ). When filled with intracellular solution, the resistance was 2.2-3.5 M $\Omega$. GFP-expressing interneurons were identified during the experiment using epifluorescence illumination. Recordings were obtained from neurons in the dentate gyrus under visual control using infrared differential interference contrast video microscopy (Stuart et al., 1993; Koh et al., 1995). BCs chosen for recording had somata located at the granule cell (GC) layer-hilus border. GCs examined had cell bodies located in the outer third of the GC layer. The recording temperature was $33-34^{\circ} \mathrm{C}$.

Two Axopatch 200B amplifiers (Molecular Devices) were used for paired recordings. Presynaptic cells were held in the I-Clamp normal mode. For the identification of passive and active membrane properties, $\mathrm{BC}$ recordings were performed in the I-Clamp fast mode. The holding potential was $-70 \mathrm{mV}$ and maintained by hyperpolarizing current injections $(<100 \mathrm{pA})$. The series resistance $\left(R_{\mathrm{s}}\right)$ in the presynaptic neuron (5-18 $\mathrm{M} \Omega$ ) was fully compensated. For paired recordings, the presynaptic neuron was stimulated at a frequency of $0.2 \mathrm{~Hz}$. Action potentials were initiated by brief current pulses (duration, $2 \mathrm{~ms}$; amplitude, $0.2-1.4 \mathrm{nA}$ ). The postsynaptic cell was held in the V-Clamp mode at $-70 \mathrm{mV}$ with $R_{\mathrm{s}}$ compensation ( $\sim 65-90 \%$; lag, $10-35 \mu \mathrm{s} ; R_{\mathrm{s}}$ before compensation, 5-12 $\mathrm{M} \Omega$ ). The stationarity of $R_{\mathrm{s}}$ in the postsynaptic neuron was assessed from the amplitude of the capacitive current in response to a $10 \mathrm{mV}$ pulse, and the compensation was readjusted during the experiment when necessary. Action potentials and IPSCs were filtered at $5-10 \mathrm{kHz}$ using the built-in four-pole, low-pass Bessel filters of the amplifiers and were digitized at $20-40 \mathrm{kHz}$ using a 1401plus laboratory interface (Cambridge Electronic Design) connected to a Pentium personal computer. Igor programs (FPulse, U. Fröbe Physiologisches Institut, Freiburg, Germany) were used for stimulus generation and data acquisition.

Antidromic action potentials were evoked in BCs by extracellular stimulation in the GC layer using glass pipettes filled with $\mathrm{Na}^{+}$-rich HEPES-buffered solution (2-3 M $\Omega$; stimulus duration, $0.2 \mathrm{~ms}$; stimulus amplitude, $<30 \mathrm{~V}$; repetition frequency, $0.2 \mathrm{~Hz}$ ). In these experiments, $10 \mu \mathrm{M}$ 6-cyano-7-nitroquinoxaline-2,3-dione (CNQX), $20 \mu \mathrm{m}$ bicuculline methiodide (BIC), and $100 \mu \mathrm{M}$ D-2-amino-5-phosphonopentanoic acid were added to the bath solution.

Solutions. The physiological extracellular solution contained (in mM) $125 \mathrm{NaCl}, 25 \mathrm{NaHCO}_{3}, 25$ glucose, $2.5 \mathrm{KCl}, 1.25 \mathrm{NaH}_{2} \mathrm{PO}_{4}, 2 \mathrm{CaCl}_{2}$, and $1 \mathrm{MgCl}_{2}$ (equilibrated with a $95 \% \mathrm{O}_{2} / 5 \% \mathrm{CO}_{2}$ gas mixture). In a subset of experiments, slices were stored in a solution containing (in $\mathrm{mM}$ ) $87 \mathrm{NaCl}$,
$25 \mathrm{NaHCO}_{3}, 2.5 \mathrm{KCl}, 1.25 \mathrm{NaH}_{2} \mathrm{PO}_{4}, 0.5 \mathrm{CaCl}_{2}, 7 \mathrm{MgCl}_{2}, 25$ glucose, and 75 sucrose. Intrinsic membrane properties from $\mathrm{BCs}$ were recorded using an intracellular solution that contained (in $\mathrm{mM}$ ) $135 \mathrm{~K}$-gluconate, 20 $\mathrm{KCl}, 0.1$ EGTA, $2 \mathrm{MgCl}_{2}, 2 \mathrm{Na}_{2} \mathrm{ATP}$, and 10 HEPES. Paired recordings and recordings during bath application of Zolpidem were performed with an intracellular solution containing (in $\mathrm{mM}$ ) $110 \mathrm{~K}$-gluconate, 40 $\mathrm{KCl}$, 0.1 EGTA, $2 \mathrm{MgCl}_{2}, 2 \mathrm{Na}_{2} \mathrm{ATP}$, and $10 \mathrm{HEPES}$; the $\mathrm{pH}$ was adjusted to 7.2 with $\mathrm{KOH}$, and the osmolarity was $310-315 \mathrm{mOsm}$. Paired recordings were performed in the presence of $10 \mu \mathrm{M} C N Q X$ in the extracellular bath solution to block EPSCs. In some experiments (five pairs), $20 \mu \mathrm{M}$ BIC was additionally added to block unitary IPSCs. BIC and tetrodotoxin (TTX) were purchased from Sigma, CNQX and Zolpidem were obtained from Tocris, and other chemicals were from Merck, Sigma, Riedel-de Haën, or Gerbu.

Data analysis. Resting membrane potential was determined immediately after transition into the whole-cell configuration. Total cell capacitance $\left(c_{\mathrm{m}}\right)$ and input resistance $\left(R_{\mathrm{in}}\right)$ were measured under voltageclamp conditions from the current during a $1 \mathrm{~s}, 10 \mathrm{mV}$ voltage pulse. To determine the membrane time constant $\left(\tau_{\mathrm{m}}\right)$, short hyperpolarizing pulses ( $0.2 \mathrm{~ms}, 0.5-1 \mathrm{nA})$ were applied in the current-clamp mode in the presence of $10 \mu \mathrm{M}$ CNQX, $20 \mu \mathrm{M}$ BIC, and $0.5 \mu \mathrm{M}$ TTX; 300-500 voltage traces were averaged; $100 \%$ to $10 \%$ of the decay was logarithmically transformed, and the late component was analyzed by linear regression. Single action potential parameters (peak amplitude, half-duration, maximal rate of rise and decay) were measured from the action potential threshold determined as the first point in the voltage trajectory in which the slope exceeded $20 \mathrm{~V} \mathrm{~s}^{-1}$ (Bekkers and Delaney, 2001). Membrane potentials reported in the text were not corrected for junction potentials.

Functional properties of unitary IPSCs were determined from averages of 10-50 traces including failures. IPSCs were aligned to the steepest point in the rise of the presynaptic action potential. The synaptic latency was determined as the time interval between the steepest point in the rise of the action potential and the onset of the IPSC; the onset point was determined from the intersection of a line through the 20 and $80 \%$ points with the baseline. The rise time of evoked IPSCs was determined as the time interval between the points corresponding to 20 and $80 \%$ of the peak amplitude. The peak current was determined as the maximum within a window of 1-4 ms duration after the presynaptic action potential. The decay phase of the IPSCs was fitted with the sum of two exponentials $\left[\mathrm{A} \exp \left(-\mathrm{t} / \tau_{1}\right)+\mathrm{B} \exp \left(-\mathrm{t} / \tau_{2}\right)\right]$, using a nonlinear least-squares fit algorithm; time constants are reported as an amplitude-weighted mean $\left[\tau_{\mathrm{w}}=\left(\mathrm{A} \tau_{1}+\mathrm{B} \tau_{2}\right) /(\mathrm{A}+\mathrm{B})\right]$. A trace was classified as failure when the peak amplitude was less than three times the SD of the baseline. Coefficients of variation (CVs; SD/mean) of synaptic latencies of unitary IPSCs were calculated from 30 to 50 traces during stationary periods.

To determine the velocity of axonal action potential propagation, antidromic action potentials were evoked in $\mathrm{BC}$ axons at four to six different stimulation sites in the GC layer. The distance between stimulation and recording site was measured on the video screen. The conduction latency was obtained as the time interval between the beginning of the stimulus artifact and the steepest point in rise of the somatically recorded action potential. Average conduction latencies were measured for 20-30 consecutive action potentials evoked at a given stimulation site. To determine the conduction velocity, average latency was plotted against distance, and data were analyzed by linear regression.

Home-made programs (Stimfit; C. Schmidt-Hieber and P. Jonas, Physiologisches Institut I, Freiburg, Germany) and Mathematica 4.1.2 (Wolfram Research) were used for data analysis. All values are given as mean \pm SEM. Significance of differences was assessed by a nonparametric two-tailed Mann-Whitney test, and correlations between two parameters were examined by Spearman rank correlation analysis; the corresponding significance levels are indicated as $p$ values.

Morphological reconstruction and analysis. Morphological analysis of BCs was performed as reported previously (Bartos et al., 2001, 2002). Neurons were filled with biocytin $(0.1-0.2 \%)$ during the recording. After withdrawal of the pipettes, slices were fixed in $2.5 \%$ paraformaldehyde, $1.25 \%$ glutaraldehyde, and $15 \%$ saturated picric acid in $100 \mathrm{~mm}$ phosphate buffer (PB), pH 7.4. Filled cells were visualized using avidin- 
biotinylated peroxidase complex and 3,3'-diaminobenzidine tetrahydrochloride (DAB) as chromogen.

Axons and dendrites of all recorded neurons were examined by light microscopy using a $63 \times$ oil-immersion objective [numerical aperture (NA) 1.4]. From all morphologically identified BCs, a subset of four young BCs (P6-P10) and five mature BCs (P18-P21) was selected for detailed morphological reconstruction using Neurolucida 7 (MicroBrightField). Morphometric data analysis was performed using NeuroExplorer (MicroBrightField).

Immunohistochemistry. For immunohistochemical double-labeling studies, biocytin-filled cells were fixed in $4 \%$ paraformaldehyde. After washing in PBS (0.025 M, pH 7.3), slices were incubated in a monoclonal antibody against $\mathrm{PV}$ (mouse; 1:10,000; Swant) in PBS containing 5\% goat serum and $0.3 \%$ Triton $\mathrm{X}-100$ for $24 \mathrm{~h}$ at $22^{\circ} \mathrm{C}$. The secondary antibody (goat anti-mouse conjugated with Alexa Fluor 568; 1:5000; Invitrogen) was applied together with streptavidin conjugated with Alexa Fluor 647 (1:500; Invitrogen) in PBS and $0.3 \%$ Triton X-100 for $6-12 \mathrm{~h}$ at $22^{\circ} \mathrm{C}$. Slices were washed in $0.1 \mathrm{M}$ PB and embedded in Prolong Antifade (Invitrogen). Labeled neurons were examined with a confocal microscope (LSM 510; Zeiss).

For a quantitative analysis on the colocalization of GAD67-GFP and PV, animals were deeply anesthetized with Narkodorm-n $(180 \mathrm{mg} / \mathrm{kg}$, i.p.; Alvetra), and the hearts were surgically exposed for perfusion fixation. First, the vascular system was flushed by circulating $0.9 \%$ saline for $1 \mathrm{~min}$. This was followed by transcardial perfusion with a freshly prepared fixative solution containing $4 \%$ paraformaldehyde in $0.1 \mathrm{M} \mathrm{PB}$ for $13 \mathrm{~min}$. After perfusion, brains were removed, and tissue blocks containing the hippocampus were cut in $50-\mu \mathrm{m}$-thick slices for PV immunohistochemistry.

To examine changes in the number and density of GAD67-GFPlabeled cells during development, confocal image stacks were taken from slice preparations of the dentate gyrus from two young ( $\mathrm{P} 9,13$ slices, 50 $\mu \mathrm{m}$ thickness) and two mature (P20, 16 slices) mice ( $40 \times$ oil-immersion objective, NA 1.3; Plan Neofluar; Zeiss). GFP-labeled cells were counted in a randomly selected $100 \times 100 \mu \mathrm{m}$ region of interest, which was centered on the GC layer (P9, total 102 cells; P20, total 98 cells). Shrinkage of slices after mounting was independent of the age $(\sim 50 \%)$, indicating that similar tissue volumes were compared.

Network simulations. Simulations were performed using a previously developed inhibitory interneuron network model (Vida et al., 2006) in the software environment of Neuron 6.1 (Hines and Carnevale, 1997). Fast-spiking interneurons were represented as single compartments endowed with voltage-gated $\mathrm{Na}^{+}$and $\mathrm{K}^{+}$conductances (Wang and Buzsáki, 1996). To reproduce the longer $\tau_{\mathrm{m}}$ and larger $R_{\mathrm{in}}$ in young interneurons, the specific leak conductance was assumed as 0.13 to 0.05 $\mathrm{mS} \mathrm{cm}{ }^{-2}$, and the membrane surface area was taken as 100 and $60 \mu \mathrm{m}^{2}$ for mature and young BCs, respectively. To mimic the action potential waveform of young BCs, we reduced the density of voltage-gated $\mathrm{Na}^{+}$ conductances from 0.035 to $0.025 \mathrm{mS} \mathrm{cm} \mathrm{cm}^{-2}$. This change resulted in action potentials with $80 \%$ peak amplitude and $175 \%$ duration compared with those in the mature modeled interneurons.

The interneuron network models were assembled from 200 neurons arranged on a virtual ring with $50 \mu \mathrm{m}$ distance between adjacent cells (Bartos et al., 2002). Each neuron was randomly connected to a subset of its 100 nearest neighbors by inhibitory synapses with a mean probability of 0.4 in young networks (this study) and of 0.6 in mature networks (Sik et al., 1995) to account for the experimentally observed differences in connection probability. Additionally, each neuron was randomly connected to four of its eight nearest neighbors by electrical synapses (transcellular conductance, $0.01 \mathrm{mS} \mathrm{cm}^{-2}$ ) (Bartos et al., 2002).

Properties of synapses in the model were based on experimental data. In the mature network, the $20-80 \%$ rise time of the conductance was set to $0.3 \mathrm{~ms}$, and the weighted decay time constant was $1.9 \mathrm{~ms}$ (Bartos et al., 2002). To model the slower conductance in the young network, the rise time was set to $0.5 \mathrm{~ms}$, and the decay time constant was $8 \mathrm{~ms}$ (present data). The synaptic latency of the postsynaptic conductance consisted of a constant synaptic delay $(0.5 \mathrm{~ms})$ and a variable conduction delay, calculated from the distance between presynaptic and postsynaptic cells along the circumference of the ring. Conduction velocity was set to
$0.25 \mathrm{~m} \mathrm{~s}^{-1}$ in the mature network and $0.13 \mathrm{~m} \mathrm{~s}^{-1}$ in the young network, and the cell-to-cell distance was reduced from 50 to $40 \mu \mathrm{m}$ to account for the reduced size of the young dentate gyrus.

Neurons were initialized to their resting membrane potential, and activity was initiated by applying tonic excitatory currents $(I)$ to each neuron with amplitudes randomly chosen from a normal distribution (with mean $I_{\mu}$ and SD $\left.I_{\sigma}\right)$. The heterogeneity of the excitatory drive $\left(I_{\sigma}\right.$ $\left./ I_{\mu}\right)$ was $10 \%$. To examine the emergence of synchronization from a disordered initial condition, driving currents were applied to individual neurons with randomized onset times taken from a uniform distribution in the range $-150 \mathrm{~ms} \leq t<-100 \mathrm{~ms}$. Chemical and electrical synapses were inactive at $-150 \mathrm{~ms} \leq t<0$ and enabled at $t=0$. In all simulations, the time step was $10 \mu \mathrm{s}$. The amplitude of the tonic excitatory current and the synaptic conductance were calculated from density values $\left(I_{\mu}=0.5-\right.$ $2.5 \mu \mathrm{A} \mathrm{cm}^{-2}$ and $g_{\text {syn }}=0.001-1 \mathrm{mS} \mathrm{cm}^{-2}$, respectively) and the surface area of mature neurons $\left(100 \mu \mathrm{m}^{2}\right)$. To account for the higher input resistance of young cells, the same current and conductance values were applied to a smaller surface of cells in networks with young intrinsic properties. The three-dimensional plots in Figure 7 indicate the density values for the mature cells. Coherence $(\kappa)$ and frequency $(f)$ values shown in Figure 7 are means of five simulations

\section{Results}

\section{Morphological identification of young BCs}

To obtain recordings from identified BCs in acute hippocampal slices, we had previously used transgenic mice expressing the enhanced GFP under the control of the PV promoter (Bartos et al., 2002; Meyer et al., 2002). However, this approach cannot be used early in postnatal development because PV expression begins at approximately P10-P14 (Du et al., 1996; Meyer et al., 2002; Tansey et al., 2002). To identify BCs at earlier developmental stages, we applied the following alternative strategy.

To identify BCs, we used a GAD67-GFP knock-in mouse line (Fig. 1) in which GABAergic cells are labeled early in development (Tamamaki et al., 2003). In acute hippocampal slices, several GFP-labeled cells were observed in the dentate gyrus in both young and mature mice (Fig. $1 A, B$ ). The density of GFP-labeled cells in the GC layer did not change significantly during postnatal development $\left(\mathrm{P} 9,7.9 \pm 0.5\right.$ cells $/ 5 \times 10^{5} \mu \mathrm{m}^{3}$; P20, $6.1 \pm 0.7$ cells $/ 5 \times 10^{5} \mu \mathrm{m}^{3} ; p>0.05$; see Materials and Methods), consistent with previous data showing that cell death is almost absent in the dentate gyrus during postnatal development (Dupuy and Houser, 1997). We first confirmed that PV-positive interneurons were labeled in this mouse line. In mature mice, double labeling revealed that $14 \%$ of GFP-expressing cells colocalized PV in the dentate gyrus (39 from 274 GFP-labeled cells in 14 slices), in agreement with $\sim 15 \%$ of $\mathrm{PV}$-immunopositive neurons within the GABAergic population in this hippocampal subregion (Kosaka and Hama, 1985). Furthermore, 43\% of GFP-positive cells with somata located in the GC layer coexpressed PV. The remaining GFP-positive cells comprised interneuron types expressing other $\mathrm{Ca}^{2+}$-binding proteins, such as calbindin and calretinin, and cells colocalizing neuropeptides, such as cholecystokinin (J. A. Hosp, I. Vida, P. Jonas, and M. Bartos, unpublished observations). These results indicate that GAD67-GFP expression is suitable for identification of PV-positive BCs in the hippocampus. We then combined GFP labeling with light-microscopical analysis of the axonal localization of neurons filled with biocytin during recording. Neurons with an axonal arborization confined to the GC layer $(>80 \%$ ), a hallmark of BCs (Buhl et al., 1994; Freund and Buzsáki, 1996; Somogyi and Klausberger, 2005), were first observed around P6 (Fig. 1C,D). Thus, in early stages of postnatal development, BCs can be unequivocally identified on the basis of GAD67-GFP expression and location of the axon in the GC layer. At later stages of postnatal development, BCs were 

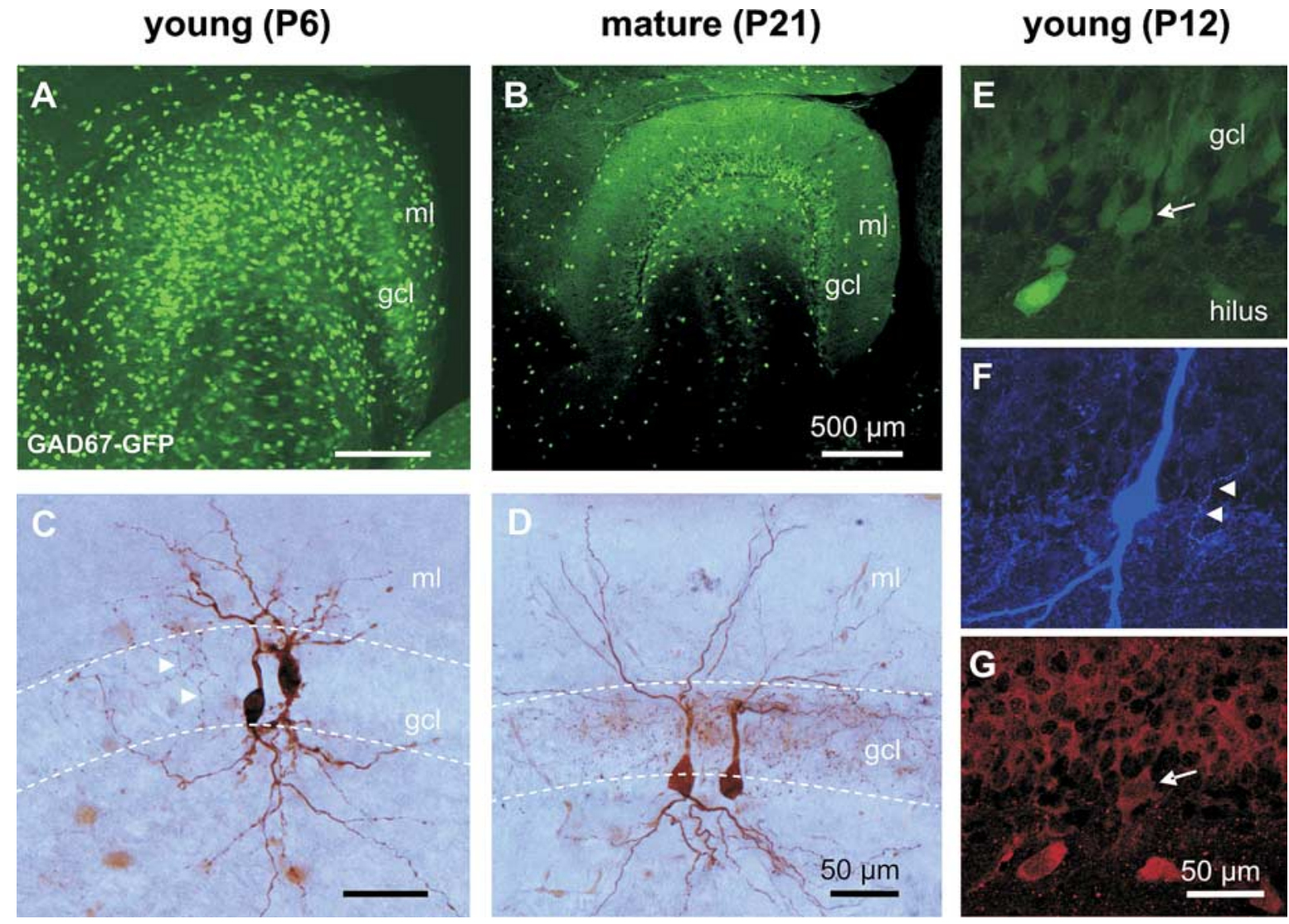

Figure 1. Morphological identification of dentate gyrus BCs in young (P6-P10) and mature (P18-P25) GAD67-GFP-expressing mice. $A, B$, Confocal image stacks from a horizontal section (50 $\mu \mathrm{m}$ ) of the dentate gyrus in a young (P6) and a mature (P21) transgenic mouse. C, D, GFP-expressing cells were filled with biocytin during the recording and subsequently visualized using DAB as chromogen. Light-microscopic images show a pair of young (left) and of mature (right) synaptically coupled BCs in the mouse dentate gyrus. Note that the axonal arborizations are located in the $G C$ layer, identifying the cells as BCs. Dashed lines indicate borders of the granule cell layer. Arrowheads point to axon collaterals. E-G, Confocal images confirm colocalization of GAD67-GFP and PV in an identified BC at P12.E, A GABAergic interneuron was identified in the slice preparation of the dentate gyrus on the basis of the GAD67-GFP signal. The arrow points to the cell body of the selected cell. $\boldsymbol{F}$, The same cell was biocytin filled and stained with Alexa Fluor 647-conjugated streptavidin. Arrowheads point to axonal collaterals in the granule cell layer. $\mathbf{G}$, The BC was identified as PV positive by immunohistochemistry. Note the weaker GFP and PV labeling of the recorded cell compared with neighboring cells because of intracellular dialysis with the pipette solution (recording time, $\sim 10 \mathrm{~min})$. Arrow points to the same cell as in $E$. gcl, Granule cell layer; $\mathrm{ml}$, molecular layer.

additionally identified immunocytochemically using an antibody against PV (Fig. $1 E-G$ ). At P12, five of five recorded BCs were PV positive. In summary, all BCs included in the present study fulfilled the criteria of GFP labeling and perisomatic location of the axon, and a subset of BCs additionally fulfilled the criterion of PV immunoreactivity.

\section{Developmental changes in morphological and intrinsic membrane properties of $\mathrm{BCs}$}

We first examined the morphological properties of BCs at different developmental stages (Fig. 2). Quantitative morphological analysis of young (P6-P10) and mature (P18-P21) BCs after reconstruction using a camera lucida revealed that dendrites and axon continue to grow during postnatal maturation, resulting in a significant increase of 354 and $608 \%$, respectively, in their total length (dendrites: $1521 \pm 298 \mu \mathrm{m}$ in four young cells vs $5387 \pm$ $1015 \mu \mathrm{m}$ in five mature cells, $p<0.05$; axon: $3871 \pm 1137 \mu \mathrm{m}$ vs $23,522 \pm 2971 \mu \mathrm{m}, p<0.001$ ) (Fig. $2 A-C$ ). At the same time, the diameter of the dendrites (e.g., second-order apical dendrites; $\mathrm{P} 6-\mathrm{P} 10,3.4 \pm 0.5 \mu \mathrm{m}$ vs P18-P21, $4.1 \pm 0.4 \mu \mathrm{m}$ ) and the axon (P6-P10, $1.3 \pm 0.2 \mu \mathrm{m} ; \mathrm{P} 18-\mathrm{P} 21,1.3 \pm 0.3 \mu \mathrm{m})$ at a distance of $15-60 \mu \mathrm{m}$ from the soma remained constant $(p>0.05)$. Axon collaterals of young BCs were primarily located ( $86 \pm 7 \%$; four cells) in the GC layer, comparable to those of the mature BCs
(81 $\pm 7 \%$; five cells). The growth of the axon was paralleled by a fivefold increase in the total number of branch points $(p<0.01)$ (supplemental Table 1, available at www.jneurosci.org as supplemental material) and increasing length of axonal segments (Fig. 2D). Thus, both the dendritic tree and the axonal arborization of BCs show substantial extension during development.

We next examined whether the observed morphological changes were accompanied by alterations in the passive membrane properties (Fig. 3). Consistent with an increase in membrane surface area $\left(\mathrm{P} 6-\mathrm{P} 10,4907.5 \pm 634.2 \mu \mathrm{m}^{2}\right.$ vs P18-P21, $14,286.6 \pm 3689 \mu \mathrm{m}^{2} ; p<0.05$ ) (supplemental Table 1, available at www.jneurosci.org as supplemental material), the total membrane capacitance $\left(c_{\mathrm{m}}\right)$ increased as a function of postnatal age from $46 \pm 4 \mathrm{pF}$ in young BCs (P6-P10, 21 cells) to $70 \pm 4 \mathrm{pF}$ in mature BCs (P18-P25, 16 cells; $p<0.001)$ (Fig. 3A). Furthermore, the input resistance $\left(R_{\text {in }}\right)$ decreased substantially from $323 \pm 38 \mathrm{M} \Omega(\mathrm{P} 6-\mathrm{P} 10)$ to $86 \pm 6 \mathrm{M} \Omega(\mathrm{P} 18-\mathrm{P} 25 ; p<0.001)$ (Fig. 3B). Finally, the membrane time constant $\left(\tau_{\mathrm{m}}\right)$ depended on postnatal age. In young cells, $\tau_{\mathrm{m}}$ was $21.9 \pm 4.3 \mathrm{~ms}$ (P6-P10, 11 cells), significantly slower than in mature neurons with $7.3 \pm 0.5$ ms (P18-P25, 13 cells; $p<0.001)$ (Fig. 3D), suggesting changes in specific membrane properties. All passive membrane parameters changed approximately exponentially as a function of postnatal age. 
A hallmark of mature BCs is the generation of brief action potentials and the ability to discharge at high frequency ( $>200 \mathrm{~Hz}$ at near-physiological temperature) in response to long depolarizing current pulses (Rudy and McBain, 2001). To test whether this spiking phenotype is also expressed in young BCs, we first analyzed the shape of somatically evoked single action potentials at various postnatal ages (Fig. 3E-H). The maximal rate of both rise and decay $\left(d V / d t_{\max }\right)$ increased significantly, resulting in a twofold reduction of the half-duration of single action potentials from $744 \pm 56 \mu$ s in young BCs to $398 \pm 36 \mu$ s in mature BCs $(p<0.001)$. Furthermore, the peak amplitude of action potentials increased as a function of postnatal age from $68 \pm 2.6 \mathrm{mV}$ at P6-P10 (14 cells) to $85.6 \pm 1.9 \mathrm{mV}$ at P18-P21 (9 cells; $p<0.05)$. Changes in action potential waveform were paralleled by a significant increase in current threshold for the initiation of single action potentials from $134.6 \pm 18.5 \mathrm{pA}$ in young BCs (13 cells) to $600 \pm 44 \mathrm{pA}$ in mature BCs (8 cells; $p<$ 0.0005). Finally, young BCs fired highfrequency trains of action potentials when stimulated with long depolarizing current injections (Fig. 3I). The frequency-current relationship was steep for both young and mature cells (data not shown); however, maximal discharge frequencies were significantly lower in young neurons (P6$\mathrm{P} 10,127.7 \pm 8 \mathrm{~Hz}, 24$ cells vs P18-P21, $263.3 \pm 26 \mathrm{~Hz}, 9$ cells; $p<0.0005$ ) (Fig. $3 J)$. To determine whether trains of action potentials evoked by long-lasting depolarizing current injections change their pattern during development, the ratio of the last and the first interspike interval at maximal discharge activity was calculated. The ratio did not change significantly during development (P6-P10, $1.4 \pm 0.04,9$ cells; $\mathrm{P} 18-\mathrm{P} 21,1.2 \pm 0.07,9$ cells; $p>0.1)$. In summary, both passive and active membrane properties of BCs are developmentally regulated, favoring slow signaling in young cells but rapid signaling in mature neurons.

\section{Velocity and reliability of action potential propagation in BC axons}

The observed developmental change in the maximal rate of rise of action potentials may lead to differences in the velocity of axonal action potential propagation between young and mature BCs. We tested this hypothesis by evoking single action potentials in BC axons by extracellular stimulation in the GC layer (Fig. 4). Antidromic action potentials were recorded at the soma under current-clamp conditions at a holding potential $\left(V_{\text {hold }}\right)$ of -70 $\mathrm{mV}$ (Fig. $4 A$ ). In young BCs, the average conduction velocity (see Materials and Methods) was low, with a mean value of $0.14 \mathrm{~m} \mathrm{~s}^{-1}$ (four cells) (Fig. $4 \mathrm{~B}$ ). In contrast, in mature BCs, the conduction velocity was almost two times higher, with a mean value of $0.25 \mathrm{~m}$ $\mathrm{s}^{-1}$ (four cells). Additionally, a pronounced jitter in the onset of somatically recorded action potentials was evident in young BCs (Fig. 4C, left). In contrast, in mature BCs, antidromic action potentials were precisely timed (Fig. $4 C$, right). To quantify temporal precision, we used the $\mathrm{CV}$ of the conduction delay between the beginning of the stimulus artifact and the time corresponding to the maximal rate of rise of the somatically recorded action potential (Fig. 4D). On average, the $\mathrm{CV}$ of the conduction delay was four times higher in young (P6-P10) than in mature (P18$\mathrm{P} 25)$ BCs $(0.08 \pm 0.01$ vs $0.02 \pm 0.002$, respectively; $p<0.01)$. Furthermore, there was a difference in the reliability of action potential propagation. To exclude stimulation failures, suprathreshold stimuli $(\sim 1.3$ times threshold $)$ were used in these experiments. In young BCs, only $83.6 \pm 0.9 \%$ of stimuli resulted in an action potential propagating to the soma, whereas in mature BCs, the reliability was $100 \%$ (Fig. $4 D$ ). Although we could not directly control for precise action potential initiation times in the axon, our data indicate that velocity, temporal precision, and reliability of action potential propagation in BC axons increased during postnatal development. 

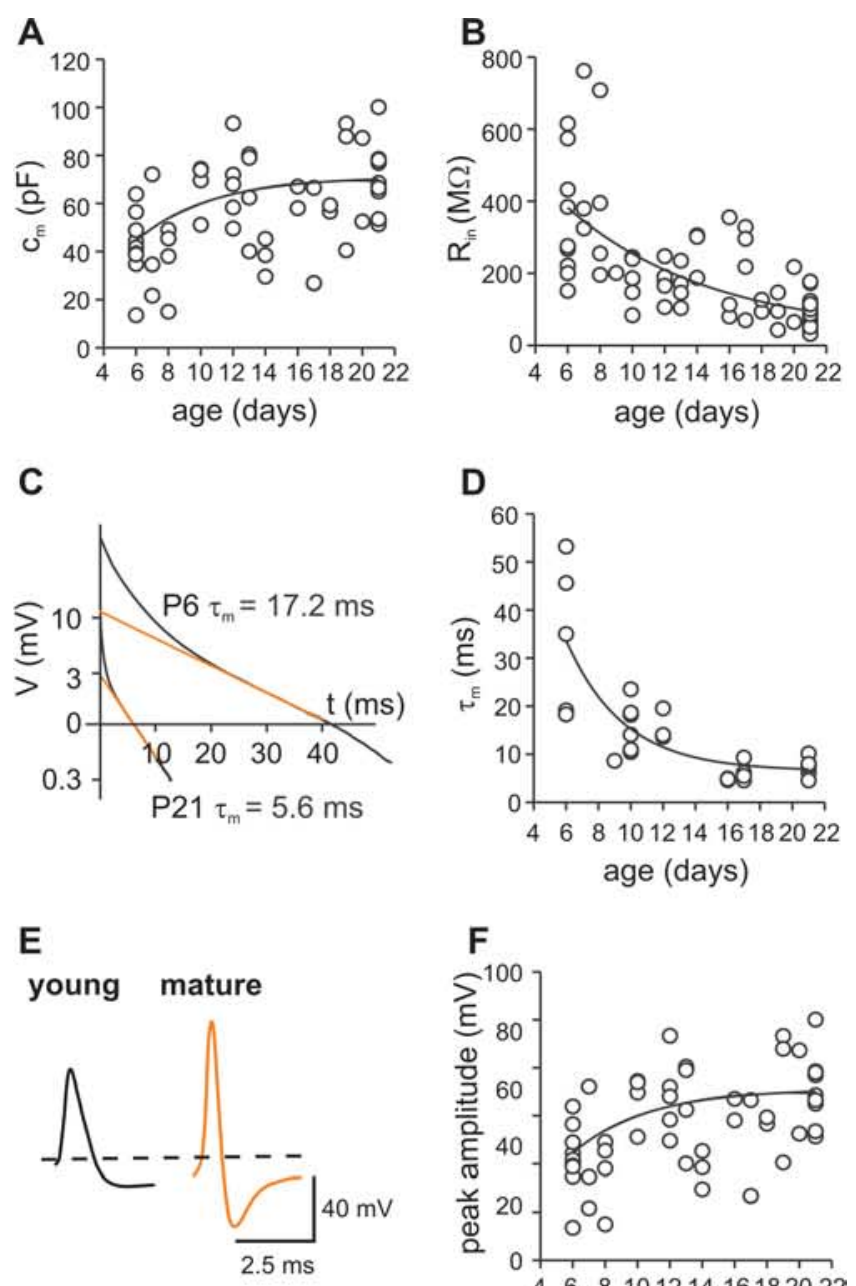

G

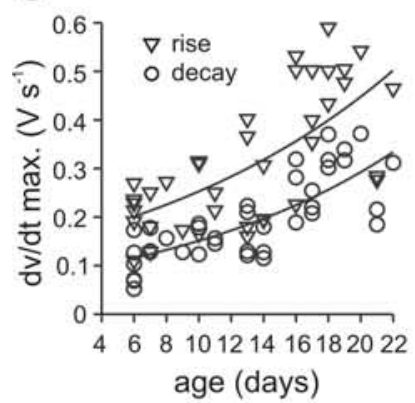

I

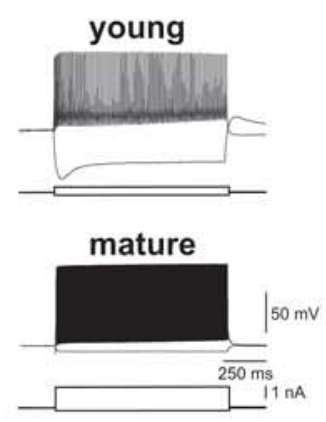

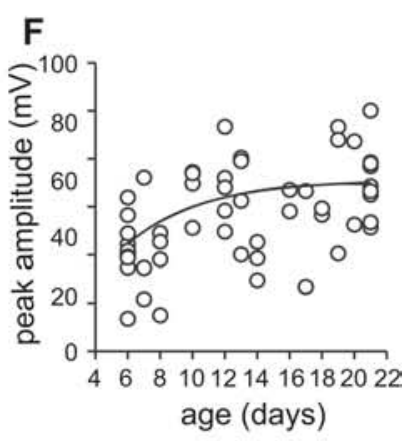

H
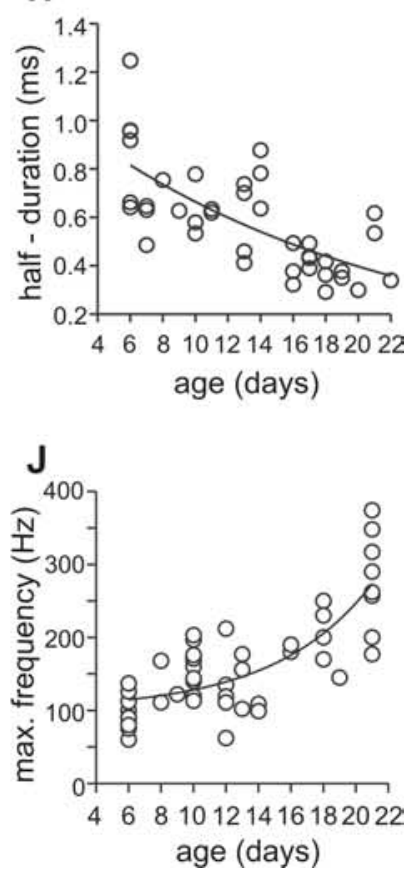

Precision and reliability of transmitter release at $\mathrm{BC}$ output synapses

To characterize developmental changes in GABAergic transmission at $\mathrm{BC}$ output synapses, we performed paired recordings from synaptically coupled BC-BC and BC-GC pairs at different postnatal ages (Fig. 5).

Young and mature BC output synapses differed in several properties of transmitter release. First, synaptic latency at BC-BC and $\mathrm{BC}-\mathrm{GC}$ synapses decreased as a function of postnatal age (Fig. $5 B$ ). The latency-age relationship could be fitted exponentially for both BC-BC and BC-GC output synapses. Because the results were not significantly different between $\mathrm{BC}-\mathrm{BC}$ and BC-GC pairs, data were pooled (Fig. 5E). Although the distance between presynaptic and postsynaptic recording sites was comparable $(44 \pm 3.8 \mu \mathrm{m})$, the mean synaptic latency was almost twofold longer at young (P6-P10) than at mature (P18-P25) BC output synapses $(1.5 \pm 0.2 \mathrm{~ms}, 15$ pairs vs $0.9 \pm 0.1 \mathrm{~ms}, 17$ pairs, respectively; $p<0.005$ ) (supplemental Table 2, available at www. jneurosci.org as supplemental material). This reduction in latency was in quantitative agreement with the increase in velocity of axonal action potential conduction (Fig. $4 \mathrm{~B}$ ), implying that the change in latency at $\mathrm{BC}-\mathrm{BC}$ and $\mathrm{BC}-\mathrm{GC}$ synapses was primarily due to the faster action potential propagation along the axon.

Second, at young BC-BC and BC-GC pairs, we observed a large jitter in synaptic latency of unitary IPSCs, suggesting imprecise GABA release (Fig. 5A). In contrast, at mature BC output synapses, latency jitter was substantially smaller, indicating that the temporal precision of GABA release increased during postnatal development. This change was most evident in the CV of the latency distribution that was used as a measure for temporal precision in transmitter release. The CV of latency decreased substantially at BC output synapses during development $(p<0.01$, respectively) (Fig. $5 C$ ) and was almost three times higher at young than at mature $B C$ synapses $(0.28 \pm 0.05,12$ pairs vs $0.1 \pm$ $0.01,10$ pairs) (Fig. $5 E$ ). This is also reflected in a reduced halfduration of the latency distribution from $1.1 \mathrm{~ms}$ in young $\mathrm{BC}$ synapses (P6-P10, 12 pairs) to $0.31 \mathrm{~ms}$ in mature $\mathrm{BC}$ synapses (P18-P25, 10 pairs; BC-BC and BC-GC synapses, pooled data) (see Fig. 8). Because the CV of synaptic latency is larger for unitary IPSCs (Fig. 5C,E) than for antidromically propagated action potentials (Fig. 4D), an increase in temporal precision of both GABA release and action potential propagation contributes to the improved timing of inhibitory signaling at $\mathrm{BC}$ output synapses.

\footnotetext{
Figure 3. Developmental changes in passive and active membrane properties of $B C s . A, B$, Summary graphs of total membrane capacitance $\left(c_{\mathrm{m}}\right)$ and input resistance $\left(R_{\text {in }}\right)$ plotted versus postnatal age. C, Logarithmic plot of voltage changes in a young (P6) and a mature (P21) BC after short $(0.2 \mathrm{~ms}$ ) hyperpolarizing (young, $0.5 \mathrm{nA}$; mature, $1 \mathrm{nA})$ current injections; regression lines (orange) are shown superimposed. $\boldsymbol{D}$, Summary graph of membrane time constant $\left(\tau_{\mathrm{m}}\right)$ plotted versus age. $\boldsymbol{E}$, Traces of single action potentials evoked during the first $5 \mathrm{~ms}$ of a $1 \mathrm{~s}$ somatic suprathreshold current injection in a young (black) and a mature (orange) BC. Both cells were held at $-70 \mathrm{mV}$ before stimulation. $\boldsymbol{F}-\boldsymbol{H}$, Summary plots of the developmental change in peak amplitude $(\boldsymbol{F})$, maximal rate of rise (triangles) and maximal rate of decay (circles; $\boldsymbol{G}$ ), and duration at half-maximal amplitude of action potentials $(\boldsymbol{H})$. Circles represent single data points. Lines correspond to exponential functions plus offset $(\boldsymbol{A}, \boldsymbol{B}, \boldsymbol{D}, \boldsymbol{F}, \boldsymbol{G}, \boldsymbol{H}, \boldsymbol{J})$ fitted to the data. I, Young (P6) and mature (P21) BCs fire high-frequency trains of action potentials when depolarized with 1-s-long positive current injections. Traces show maximal discharges of a young and a mature $B C$ (young $B C, 300 \mathrm{pA}$; mature $B C, 950 \mathrm{pA}$ ) and are superimposed with hyperpolarizing traces evoked by a negative current injection ( $-100 \mathrm{pA}$ in both cells). J, Maximal discharge frequency plotted as a function of age. Each circle represents the average frequency calculated from the inverse of the interspike intervals in trains of action potentials. max., Maximal.
} 
Finally, probability of failures in GABAergic transmission decreased markedly during postnatal development at BC-BC synapses (young, $32 \pm 11 \%$ vs mature, $4.5 \pm 3 \%$; $p<0.05$ ) (supplemental Table 2, available at www.jneurosci.org as supplemental material) and $\mathrm{BC}-\mathrm{GC}$ synapses (young, $42 \pm 5 \%$ vs mature, $2 \pm 2 \%$; $p<0.005)$ (Fig. $5 D, E$ ). Failures at output synapses of young BCs can be largely explained by the stochastic properties of transmitter release and partially $(\sim 16 \%)$ by the unreliable action potential propagation along the axon.

In contrast to the marked changes in chemical transmission during development, we observed significant changes neither in the incidence of electrical coupling among BCs (P6-P14, 9.5\%; P18-P25, $11 \%)$ nor in the ratio of electrical coupling at BC-BC pairs (P6-P14: $0.013 \pm 0.01$, four pairs; P18-P25: $0.011 \pm 0.01$, five pairs), consistent with previous reports in the neocortex (Long et al., 2005). In summary, BC output synapses undergo marked developmental changes in the properties of transmitter release, leading to a developmental shift from imprecise and unreliable to precise and reliable signaling devices.

\section{Increased peak amplitude and accelerated decay time course of unitary IPSCs}

Light-microscopic analysis of intracellularly labeled $\mathrm{BC}-\mathrm{BC}$ and $\mathrm{BC}-\mathrm{GC}$ pairs showed that putative output synapses of both young (Fig. 1) and mature BCs (Geiger et al., 1997; Bartos et al., 2001) are located close to the soma of their target cells.

This allowed us to measure the postsynaptic inhibitory conductance change as IPSCs in the voltage-clamp configuration at various postnatal ages (Fig. 6).

During maturation, a fourfold increase in the peak amplitude of unitary IPSCs (Fig. 6B) was observed at both BC-BC (P6-P10, $27 \pm 5 \mathrm{pA}, 4$ pairs vs $\mathrm{P} 18-\mathrm{P} 25,104 \pm 24 \mathrm{pA}, 7$ pairs; $p<0.01$ ) and BC-GC (P6-P10, $37 \pm 19 \mathrm{pA}, 11$ pairs vs $\mathrm{P} 18-\mathrm{P} 25,148 \pm 34$ $\mathrm{pA}, 10$ pairs; $p<0.01$ ) synapses (supplemental Table 2, available at www.jneurosci.org as supplemental material). This increase in synaptic strength was paralleled by a growing probability of obtaining paired $\mathrm{BC}-\mathrm{BC}$ recordings from $7 \%$ at $\mathrm{P} 6-\mathrm{P} 8$ to $15 \%$ at P18-P25 (Fig. 6C). Similarly, the connection probability for BC-GC synapses increased from $10 \%$ at P6-P8 to $55 \%$ at P18$\mathrm{P} 25$. These data together indicate that both the number of target cells and the number of contact sites per target cell increase during maturation, consistent with the observed extension of the axonal arborization. Paired recording analysis also revealed a marked decrease in the amplitude-weighted decay time constant $\left(\tau_{\mathrm{w}}\right)$ of unitary IPSCs at both BC-BC (P6-P10, $7.5 \pm 1.5 \mathrm{~ms}$ vs $\mathrm{P} 18-\mathrm{P} 25,2.0 \pm 0.2 \mathrm{~ms} ; p<0.0005)$ and BC-GC (P6-P10, $8.8 \pm 1.4 \mathrm{~ms}$ vs P18-P25, $4.4 \pm 0.5 \mathrm{~ms} ; p<$ 0.005 ) synapses (Fig. $6 B$ ). Intriguingly, the relative differences between $\mathrm{BC}-\mathrm{BC}$ and $\mathrm{BC}-\mathrm{GC}$ synapses were small in the young dentate gyrus but became greatly accentuated during development ( $p<0.005$ at P18-P25). Thus, the maturation of the fast kinetics of inhibition is target-cell specific.

It has been suggested that the $\alpha 1$ subunit is a key molecular determinant of rapid kinetics of recombinant $\mathrm{GABA}_{\mathrm{A}}$ receptors (Lavoie et al., 1997; Cope et al., 2005) and that the postsynaptic sites of BC-BC synapses are highly enriched in $\alpha 1$ subunit immunoreactivity (Fritschy and Möhler, 1995; Nusser et al., 1995; Klausberger et al., 2002). To probe the $\alpha 1$ content of BC-BC synapses in young and mature hippocampus, we tested the effects of the $\mathrm{GABA}_{\mathrm{A}}$ receptor modulator Zolpidem (Fig. 6D). At low concentrations, Zolpidem selectively affects $\mathrm{GABA}_{\mathrm{A}}$ receptors assembled from $\alpha 1 \beta \gamma 2$ subunits (Thomson et al., 2000; Cope et al., 2005). The addition of $5 \mu \mathrm{M}$ Zolpidem to the bath solution significantly increased $\tau_{\mathrm{w}}$ of compound IPSCs evoked by extracellular stimulation in the GC layer in mature cells (159.6 $\pm 36 \%$; six cells), indicating the presence of $\alpha 1$ subunits. In contrast, no significant effect was observed on $\tau_{\mathrm{w}}$ of IPSCs recorded in young neurons $(8.5 \pm 16 \%$; five cells), suggesting that their synapses are devoid of $\alpha 1$ subunits. Thus, the developmental acceleration of the unitary IPSC decay time course at BC-BC synapses can be 
A

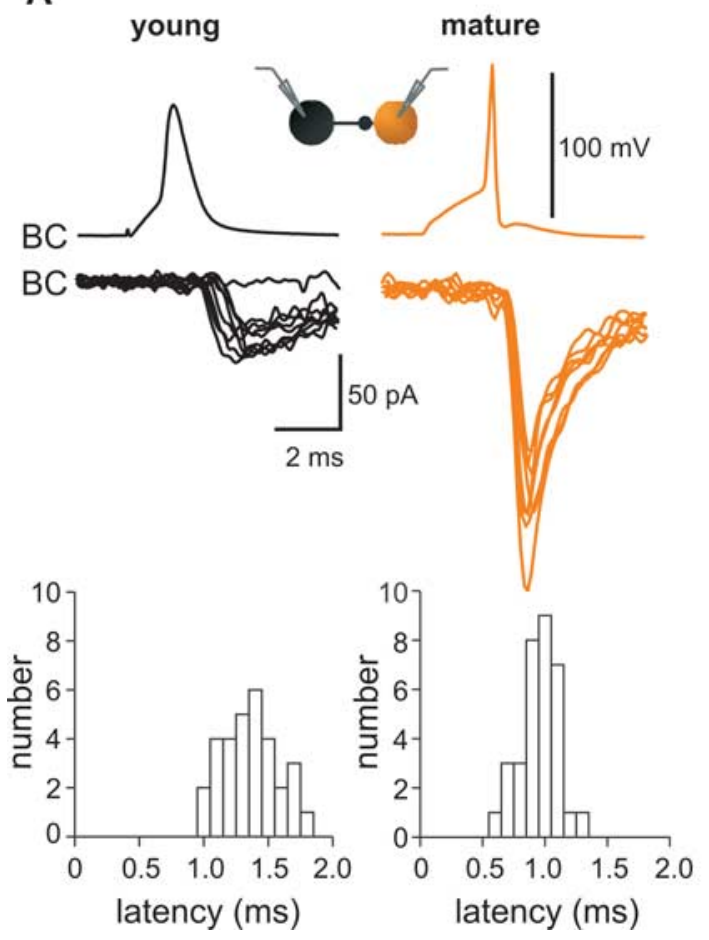

B

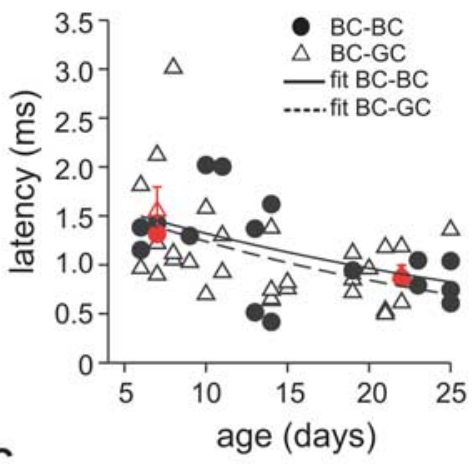

C

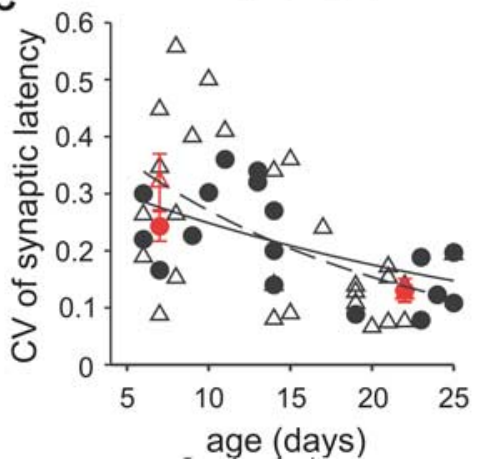

D

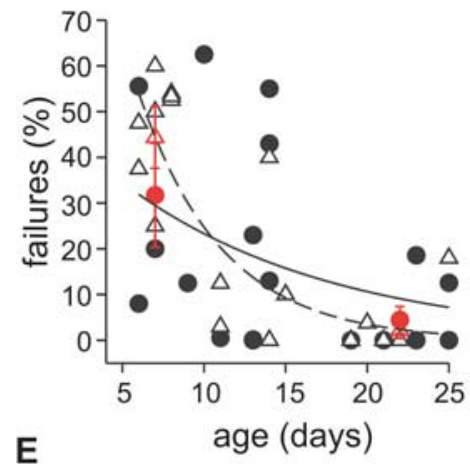

E
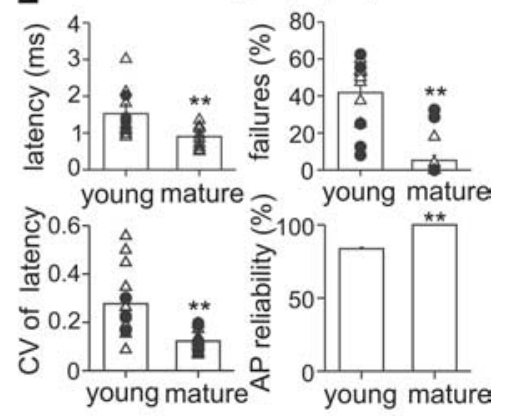

Figure 5. Precision of quantal GABA release at BC output synapses increases during postnatal development. $A$, Single action potentials (top traces) evoke single unitary IPSCs (bottom traces) in a young (P6; left) and a mature (P21; right) BC-BC pair. Eight unitary IPSCs are superimposed. Synaptic latency histograms of unitary IPSCs are shown below the traces for the same paired recordings (left, young $B C-B C$ pair; right, mature $B C-B C$ pair). $\boldsymbol{B}-\boldsymbol{D}$, Summary plot of synaptic latencies $(\boldsymbol{B})$, the $C V$ of synaptic latencies $(\boldsymbol{C})$, and the proportion of transmission failures ( $\boldsymbol{D})$, at both $B C-B C$ (filled circles) and $B C-G C$ (open triangles) synapses at various postnatal ages. Lines correspond to exponential functions fitted to the data from $B C-B C$ (continuous line) and $B C-G C$ (dashed line) pairs. Red circles represent average values from $B C-B C$ pairs, and red triangles represent average values from $B C-G C$ pairs in the age range of $P 6-P 10$ and of $P 18-P 25$. E, Summary bar graphs of synaptic latency, CV of synaptic latencies, and transmission failures at young (P6-P10) and mature (P18-P25) BC-BC (filled circles) and BC-GC (open triangles) synapses. The bottom right bar graph summarizes the reliability of antidromic action potentials (AP) recorded at the soma of young and mature $\mathrm{BC}$ s during extracellular stimulation in the $\mathrm{GC}$ layer for direct comparison. ${ }^{* *} p<0.01$.

explained by a change in the subunit composition, especially a higher $\alpha 1$ content of postsynaptic $\mathrm{GABA}_{\mathrm{A}}$ receptors.

\section{Generation of gamma oscillations in young interneuron network models}

The functional properties of mature BCs appear to be optimized for the generation of synchronous gamma frequency oscillations in interneuron networks (Bartos et al., 2001, 2002, 2007; Vida et al., 2006). However, the present results indicate that the properties of young BCs are very different from those of mature cells. Can interneuron networks with young intrinsic and synaptic properties support synchronization at gamma frequencies?

To answer this question, we modified stepwise our previously developed interneuron network model (Vida et al., 2006) to reproduce salient experimentally determined properties of young BCs and examined the effects of these changes on coherence and frequency of network oscillations (Fig. 7). As shown previously, the mature interneuron network with fast action potential conduction $\left(0.25 \mathrm{~m} \mathrm{~s}^{-1}\right)$, rapid IPSCs $\left(\tau_{\mathrm{w}}=2 \mathrm{~ms}\right.$ ), and high connectivity (mean number of postsynaptic neurons, $M_{\text {syn }}=60$ ) (Sik et al., 1995) generated highly coherent oscillations in the upper gamma frequency band (maximal $\kappa=0.74$ at a network frequency of $56 \mathrm{~Hz}$ ) when activated by a low, moderately heterogeneous tonic excitatory drive $\left(I_{\mu}=0.5-2.5 \mu \mathrm{A}\right.$ $\mathrm{cm}^{-2} ; I_{\sigma /} I_{\mu}=0.1$ ) (Fig. 7A,B) [Vida et al. (2006), their Fig. 3B]. Introduction of young intrinsic properties to the mature network, including slow membrane time constant, broad action potential waveform, and low conduction velocity $\left(0.13 \mathrm{~m} \mathrm{~s}^{-1}\right)$, resulted in a reduction in both network coherence and frequency (maximal $\kappa=$ 0.7 at $43 \mathrm{~Hz}$, Fig. 7C). Similarly, when the time course of IPSCs was slowed to match the measured values in young BCs $\left(\tau_{\mathrm{w}}=8 \mathrm{~ms}\right)$, both peak coherence and network frequency were reduced (maximal $\kappa=0.68$ at $39 \mathrm{~Hz}$ ) (Fig. 7D). When connectivity was reduced in the mature network $\left(M_{\text {syn }}=40\right)$, the peak coherence dropped markedly (maximal $\kappa=0.57$ ), whereas the corresponding network frequency remained high $(56 \mathrm{~Hz})$ (Fig. $7 E$ ). Interestingly, when slow intrinsic properties and slow IPSCs were combined in the networks, gamma oscillations with high coherence but low frequency emerged (maximal $\kappa=0.89$ at $34 \mathrm{~Hz}$ ) (Fig. $7 F$ ). In contrast, when low connectivity was combined to the slow intrinsic properties or slow IPSCs, coherence was further reduced $(0.39$ at $55 \mathrm{~Hz}$ and 0.56 at 44 $\mathrm{Hz}$, respectively) (Fig $7 G, H)$. Finally, when all three properties were introduced together, to reproduce an immature interneuron network, oscillations were generated with low coherence in the lower gamma frequency band (maximal $\kappa=0.49$ at $34 \mathrm{~Hz}$ ) (Fig. $7 \mathrm{I}, J)$.

In summary, our data show that intrinsic, synaptic, and structural properties of interneuron networks are important parameters that jointly define coherence and frequency of network oscillations. Changes in the intrinsic properties and the kinetics of ISPCs act synergistically to promote oscillations, first in the lower and later in the upper gamma frequency band during postnatal maturation. In contrast, increasing network connectivity promotes synchrony in the neuron network and thereby underlies the increasing power of oscillations as observed in the developing brain (Lahtinen et al., 2002).

\section{Discussion}

Dentate gyrus BCs undergo marked changes in their morphological, intrinsic, and synaptic properties at P6-P25 (Fig. 8). First, 
membrane time constant, action potential waveform, and axonal conduction velocity become faster. Second, precision, strength, and reliability of transmitter release increase at BC output synapses. Finally, kinetics of unitary IPSCs become rapid. Thus, concerted changes, presumably driven by a complex genetic program, convert BCs from slow to fast signaling devices during the late postnatal period. Our computational analysis also reveals that combined changes in cellular and synaptic properties of BCs can support the developmental increase in frequency and coherence of gamma oscillations observed in vivo (Lahtinen et al., 2002).

\section{Developmental changes in BC morphology}

Size and functional properties of BC dendrites change substantially during development. The total dendritic length increases 3.5-fold at P6-P21 (Fig. 2). In correlation with the associated enlargement in surface area, we found an increase in the apparent membrane capacitance $\left(c_{\mathrm{m}}\right)$ and a decrease in input resistance $\left(R_{\text {in }}\right)$ and membrane time constant $\left(\tau_{\mathrm{m}}\right)$ (Fig. $3 A-D)$. Because the capacitance of lipid membranes is relatively constant $(\sim 1$ $\mu \mathrm{F} \mathrm{cm}^{-2}$ ) (Hille, 2001), the latter changes indicate a decrease in specific membrane resistance $\left(R_{\mathrm{m}}\right)$. Our results therefore suggest major changes in the extent and the integrative properties of $\mathrm{BC}$ dendrites.

The developmental reduction in $R_{\mathrm{m}}$ could be explained by increases in densities of leak channels (e.g., two-pore domain $\mathrm{K}^{+}$channels) (Taverna et al., 2005; Torborg et al., 2006). Changes in morphology and membrane properties jointly redefine somatodendritic integration of EPSPs in BCs. In young BCs, the size of the dendritic tree is smaller, $R_{\mathrm{i}}$ is higher, and $\tau_{\mathrm{m}}$ is slower than in mature BCs. The combination of these properties favors spatial and temporal integration of synaptic inputs in young BCs but coincidence detection in mature BCs.

Substantial changes during development also occur in BC axons. The total length of the axon increases sixfold at P6-P21 (Fig. 2 ). In parallel, the probability of obtaining paired recordings increases approximately twofold (Fig. 6C). Thus, axon maturation will lead to the innervation of a higher number of target cells in a larger area. Within the same developmental window, velocity and reliability of axonal action potential propagation also increases (Fig. $4 B, D$ ), supporting rapid and reliable synaptic transmission, a prerequisite for the function of mature BC synapses (Bartos et al., 2001, 2002). Both structural and functional changes could explain the increase in conduction velocity and synchrony of transmitter release (Williams et al., 1998). Faster action potential propagation may be caused by a larger axon diameter; however, we found comparable axon diameters in young and mature cells. Alternatively, an enhanced density of voltage-dependent $\mathrm{Na}^{+}$ channels in BC axons may be responsible (Jack et al., 1975). Con-
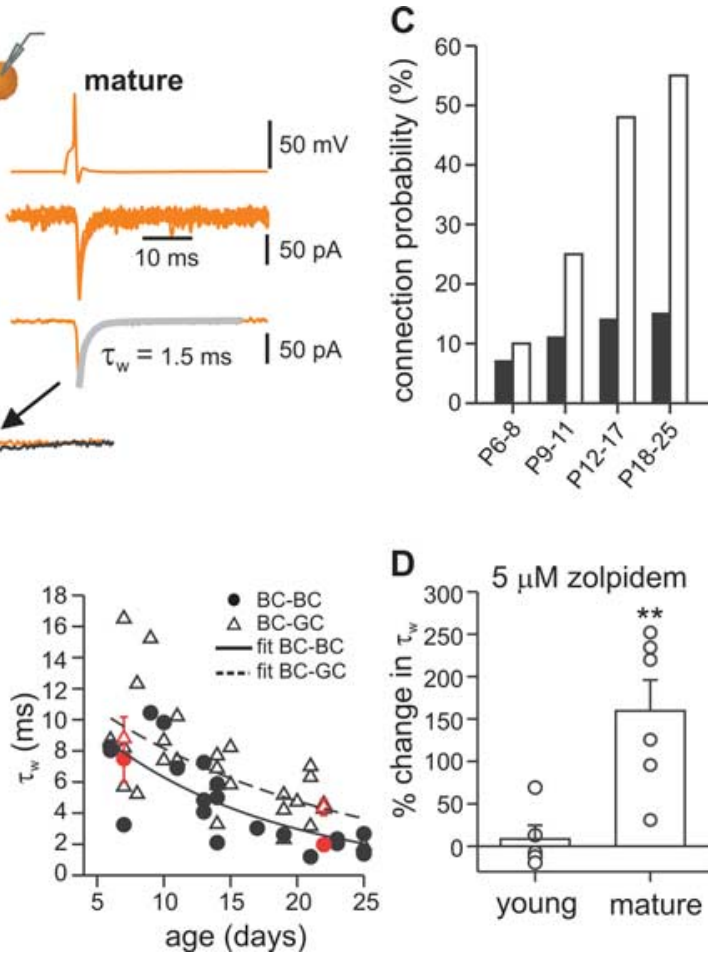

Figure 6. Unitary inhibitory postsynaptic conductance at $B C$ output synapses becomes stronger and faster during postnatal connected; P18-P25, 10 of 18 connected). D, Zolpidem (5 $\mu \mathrm{m})$, a benzodiazepine type I receptor agonist, increases the decay time constant $\left(\tau_{\mathrm{w}}\right)$ of IPSCs evoked by extracellular axon stimulation in mature but not in young $\mathrm{BCs} .{ }^{* *} p<0.01$.

sistent with this hypothesis, we found that maximal rate of rise of axonal action potentials is twofold faster in mature than in young BCs (Fig. 3G). An increasing $\mathrm{Na}^{+}$channel density in developing BCs not only explains the observed change in conduction velocity but also the increased reliability of action potential propagation. This effect may further be supported by increases in myelination of $\mathrm{BC}$ axons. However, this hypothesis needs additional experimental proof. Collectively, developmental changes in BC axons lead to a situation in which BCs innervate a higher number of target cells in a larger area with shorter delays and increased reliability.

\section{Developmental changes at $\mathrm{BC}$ output synapses}

GABAergic transmission at BC output synapses is characterized by a threefold higher synchrony at mature than at young synapses (Fig. $5 B, C, E$ ). The $\mathrm{CV}$ of synaptic latency is much larger than that of action potential conduction velocity in young BCs, indicating that the lower synchrony can only partly be explained by variable and slow spike propagation.

Several mechanisms may contribute to the enhanced synchro- 
A

B mature network
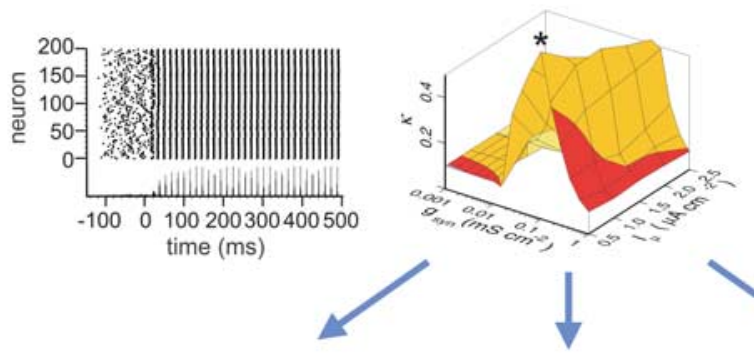

C young intrinsic prop.

D slow IPSCs

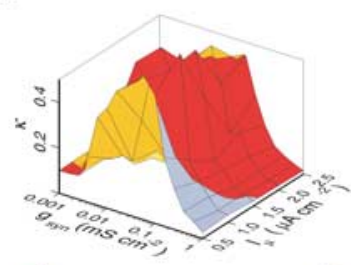

\section{E low connectivity}
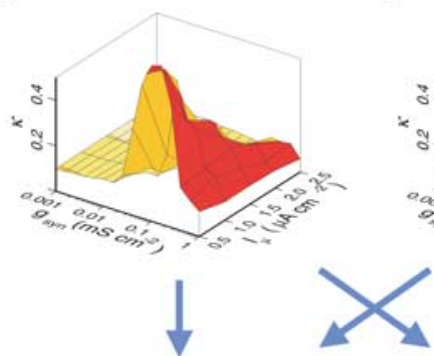

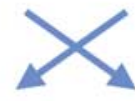

H

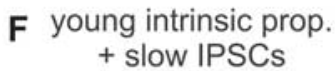

G young intrinsic prop.
+ low connectivity
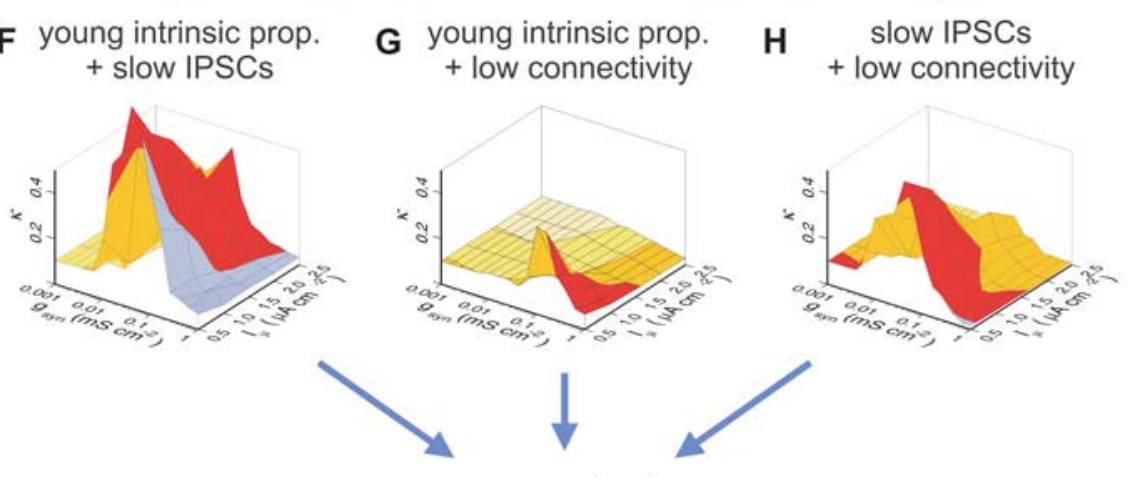

\section{I young network}

$\mathbf{J}$
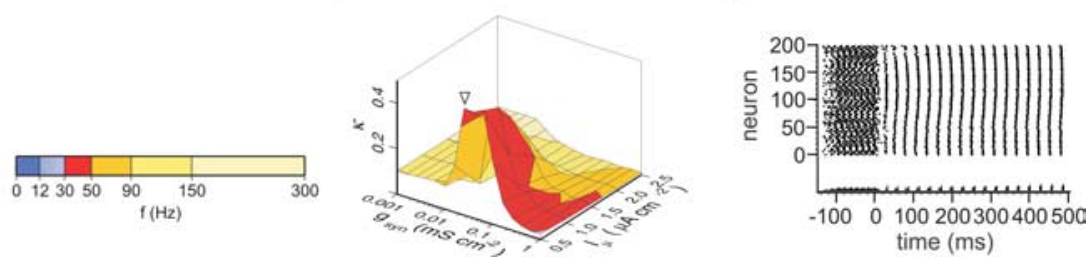

Figure 7. Difference in coherence levels and frequency tuning of young and mature interneuron network models. $A$, Raster plot illustrates the activity of the interneuron network model with mature properties at the maximal coherence level. Each dot represents an action potential during one simulation run $(-150$ to $500 \mathrm{~ms})$; index of neurons $(1-200)$ is plotted on the $y$-axis. The graph below the raster plot represents the spike-time histogram (bin width, $1 \mathrm{~ms}$; maximal amplitude, 100 neurons). Tonic excitation was applied at random time points $(-150 \mathrm{~ms} \leq t<-100 \mathrm{~ms})$; inhibitory synapses were enabled at $\mathrm{t} \geq 0 \mathrm{~ms}$. Coherence was determined during the last $100 \mathrm{~ms}$ of the simulation period. $\boldsymbol{B}-\boldsymbol{I}$, Three-dimensional plots of the coherence measure $\kappa$ versus the tonic excitatory drive $\left(I_{\mu}\right)$ and the unitary peak conductance $\left(g_{\text {syn }}\right)$. The height of the peaks in the three-dimensional plots indicates the level of synchrony in the network, quantified by $\kappa$. Corresponding network frequencies $\left(f_{\mu}\right)$ are indicated by the color code superimposed on the surface of the plots (see scale bar at the bottom). The heterogeneity of the excitatory drive $\left(I_{\sigma} l_{\mu}\right)$ was $10 \%$; the reversal potential of the inhibitory conductance was $-55 \mathrm{mV}$, reflecting shunting inhibition between P6 and P25 (Chavas and Marty, 2003; Vida et al., 2006; Banke and McBain, 2007). For additional details, see Materials and Methods. Simulations were started with a mature network $(\boldsymbol{B})$. Subsequently, intrinsic, synaptic, and network parameters were changed stepwise to reproduce properties of the young network $(\boldsymbol{I})$. The mature interneuron network (B) generates gamma oscillations with high coherence (maximal $\kappa=0.74$ ) in the upper gamma frequency range ( $50-90 \mathrm{~Hz}$; orange). Introduction of young intrinsic properties (prop.), including slow intrinsic membrane properties, broad action potentials, and slow action potential conduction velocity ( ) or slow decay of the IPSC (D), decreases coherence and reduces network frequency to the lower gamma range $\left(30-50 \mathrm{~Hz}\right.$; red). Introduction of low network connectivity $\left(\boldsymbol{E} ; M_{\text {syn }}=40\right)$ also reduces coherence, but it keeps oscillatory frequency largely unchanged ( $50-90 \mathrm{~Hz}$; yellow). Surprisingly, the combination of young intrinsic properties with slow IPSCS $(\boldsymbol{F})$ results in an increase in peak coherence, whereas network frequency remains low. In contrast, the combination of low connectivity with young intrinsic properties $(\boldsymbol{G})$ or slow IPSCS $(\boldsymbol{H})$ results in a further marked reduction in coherence. When all properties are combined to simulate the young network $(I)$, oscillations are generated at low coherence (maximal $\kappa=0.39$ ) in the lower gamma range $(30-50 \mathrm{~Hz})$. $J$, Raster plot of network activity in a network with young properties at the maximal level of coherence. The asterisk and triangle in $\boldsymbol{B}$ and $\boldsymbol{I}$ indicate parameter settings for the raster plots. nization of transmitter release. First, a reduction in presynaptic action potential duration may occur. Indeed, we found a substantial developmental shortening of somatic action potentials in BCs (Fig. $3 H$ ). Similar changes at presynaptic sites would explain increases in synchrony of transmitter release. Consistent with this hypothesis, the density of Kv3-type potassium channels, a major determinant of action potential repolarization in interneurons (Rudy and McBain, 2001), increases during development ( $\mathrm{Du}$ et al., 1996; Tansey et al., 2002). Second, properties of presynaptic $\mathrm{Ca}^{2+}$ channels may change developmentally. Indeed, transmitter release at $\mathrm{BC}$ output synapses depends on $\mathrm{N}$ - and $\mathrm{P} / \mathrm{Q}$-type channels in young BCs (M. Bartos, unpublished observations) but relies exclusively on P/Q-type channels in mature cells (Hefft and Jonas, 2005). Coupling of these channels to the release machinery appears to be different. $\mathrm{P} / \mathrm{Q}$ type are coupled more tightly to the release machinery than $\mathrm{N}$-type channels, leading to sharper $\mathrm{Ca}^{2+}$ transients at the $\mathrm{Ca}^{2+}$ sensor (Bucurenciu et al., 2008). Finally, it is possible that properties of the exocytotic machinery change. For example, the expression of synaptotagmins, the putative $\mathrm{Ca}^{2+}$ sensors, is developmentally regulated (Berton et al., 1997). Thus, different presynaptic changes may converge to synchronize transmitter release. Indeed, combined presynaptic alternations underlying synchronization of transmitter release during development were reported at the calyx of Held (Taschenberger and von Gersdorff, 2000; Yang and Wang, 2006).

Additional developmental changes take place at postsynaptic sites of $\mathrm{BC}$ output synapses. The decay time constant of unitary IPSCs is approximately fourfold faster at mature than at young synapses (Fig. 6). How can we explain these changes? In situ hybridization and immunohistochemical data suggest changes in the subunit composition of $\mathrm{GABA}_{\mathrm{A}}$ receptors during development. Although $\alpha 2$ subunits are highly expressed at early stages, $\alpha 1$ subunits are upregulated at later times (Laurie et al., 1992; Fritschy and Möhler, 1995). Immunocytochemical analysis revealed that mature BC output synapses are highly enriched in $\alpha 1$ subunits (Klausberger et al., 2002). $\mathrm{GABA}_{\mathrm{A}}$ receptors containing $\alpha 1$ deactivate faster than those with $\alpha 2$ (Lavoie et al., 1997). Thus, a developmental switch in subunit composition of postsynaptic $\mathrm{GABA}_{\mathrm{A}}$ receptors could explain changes in IPSC kinetics. This hypothesis is consistent with our result that IPSCs are sensitive to the $\alpha 1$-selective ben- 
zodiazepine agonist Zolpidem at mature but not at young BC synapses (Fig. 6D).

\section{Implications for network function}

Developmental alterations in $\mathrm{BC}$ properties have several implications for neuronal network function. First, we predict that young and mature BCs are differentially involved in feedforward and feedback inhibition. Young BCs integrate asynchronous inputs, generate low-frequency trains of action potentials (this study; Daw et al., 2007), and elicit weak and slow IPSCs in their target neurons. Thus, young $\mathrm{BCs}$ generate a slow form of inhibition. In contrast, mature BCs detect coincident excitatory inputs, generate high-frequency trains of action potentials (present results; Geiger et al., 1997; Galarreta and Hestrin, 2001; Penttonen et al., 1998), and generate a fast inhibitory synaptic output, providing phasic inhibition with high temporal precision to their targets (Hefft and Jonas, 2005). Thus, fast signaling properties of mature BCs contribute to speed and temporal precision of feedforward and feedback inhibition (Pouille and Scanziani, 2001, 2004; Galarreta and Hestrin, 2002). These developmental changes may account for the sharpening of place fields of GCs and the emergence of critical periods of synaptic plasticity during development (Martin and Berthoz, 2002; Hensch, 2005).

Developmental changes in $\mathrm{BC}$ signaling are relevant for the generation of network oscillations. Experimental and theoretical evidence indicate that mature BCs play a key role in the generation of robust gamma oscillations in vitro and in vivo (Bragin et al., 1995; Whittington et al., 1995; Traub et al., 1996, 2004; Wang and Buzsáki, 1996; Fisahn et al., 1998; Towers et al., 2002; Csicsvari et al., 2003). BCs form networks via mutual inhibitory synapses, and the decay time constant of IPSCs at BC synapses has been identified as key parameter setting frequency and coherence of network oscillations (M. Bartos, unpublished observations; Traub et al., 1996; Wang and Buzsáki, 1996; Cope et al., 2005). During postnatal development, gamma activity emerges at the end of the first postnatal week (Lahtinen et al., 2002; Leinekugel et al., 2002). However, frequency and coherence of the oscillations are low at this stage and reach adult levels only by the fourth postnatal week. This time course corresponds well to the appearance and subsequent functional maturation of $\mathrm{BC}$-mediated inhibition observed in this study. Our simulations reveal that neuronal networks with immature properties generate gamma oscillations (Fig. 7), but with markedly lower frequency and coherence than those with mature characteristics (Bartos et al., 2002; Vida et al., 2006). Whereas changes in intrinsic and synaptic properties of BCs set the frequency of the oscillations, changes in connectivity can explain the developmental increase in coherence of gamma activity observed in vivo (Lahtinen et al., 2002). Although our network model reproduces adequately gamma oscillations in young (Lahtinen et al., 2002) and mature (Bragin et al., 1995; Penttonen et al., 1998) animals in vivo, the next challenge is to determine how interactions among various neuron types contribute to developmental changes in network dynamics.

In summary, our results show that, during late postnatal development, BCs differentiate functionally from slow to fast signaling devices. Changes in morphological, intrinsic and synaptic properties of BCs associated with this process are crucial for the emergence of robust and highly coherent gamma oscillations and may thereby contribute to the maturation of higher cognitive brain functions in both rodents and humans (Ben-Ari et al., 2007; Yurgelun-Todd, 2007).

\section{References}

Banke TG, McBain CJ (2007) GABAergic input onto CA3 hippocampal interneurons remains shunting throughout development. J Neurosci 26:11720-11725.

Bartos M, Vida I, Frotscher M, Geiger JRP, Jonas P (2001) Rapid signaling at inhibitory synapses in a dentate gyrus interneuron network. J Neurosci 21:2687-2698.

Bartos M, Vida I, Frotscher M, Meyer A, Monyer H, Geiger JRP, Jonas P (2002) Fast synaptic inhibition promotes synchronized gamma oscillations in hippocampal interneuron networks. Proc Natl Acad Sci USA 99:13222-13227.

Bartos M, Vida I, Jonas P (2007) Synaptic mechanisms of synchronized gamma oscillations in inhibitory interneuron networks. Nat Rev Neurosci 8:45-56.

Bekkers JM, Delaney AJ (2001) Modulation of excitability by $\alpha$-dendrotoxin-sensitive potassium channels in neocortical pyramidal neurons. J Neurosci 21:6553-6560.

Ben-Ari Y, Gaiarsa JL, Tyzio R, Khazipov R (2007) GABA: a pioneer transmitter that excites immature neurons and generates primitive oscillations. Physiol Rev 87:1215-1284.

Berton F, Iborra C, Boudier JA, Seagar MJ, Marquèze B (1997) Developmental regulation of synaptotagmin I, II, III, and IV mRNAs in the rat CNS. J Neurosci 17:1206-1216.

Bragin A, Jandó G, Nádasdy Z, Hetke J, Wise K, Buzsáki G (1995) Gamma $(40-100 \mathrm{~Hz})$ oscillation in the behaving rat. J Neurosci 15:47-60.

Bucurenciu I, Kulik A, Schwaller B, Frotscher M, Jonas P (2008) Nanodomain coupling between $\mathrm{Ca}^{2+}$ channels and $\mathrm{Ca}^{2+}$ sensors promotes fast and efficient transmitter release at a cortical GABAergic synapse. Neuron 57:536-545.

Buhl EH, Halasy K, Somogyi P (1994) Diverse sources of hippocampal unitary inhibitory postsynaptic potentials and the number of synaptic release sites. Nature 368:823-828.

Buzsáki G (2006) Rhythms of the brain. New York: Oxford UP.

Buzsáki G, Draguhn A (2004) Neuronal oscillations in cortical networks. Science 304:1926-1929.

Chavas J, Marty A (2003) Coexistence of excitatory and inhibitory GABA synapses in the cerebellar interneuron network. J Neurosci 23:2019-2031.

Cohen AS, Lin DD, Coulter DA (2000) Protracted postnatal development of 
inhibitory synaptic transmission in rat hippocampal area CA1 neurons. J Neurophysiol 84:2465-2476.

Cope DW, Halbsguth C, Karayannis T, Wulff P, Ferraguti F, Hoeger H, Leppä E, Linden AM, Oberto A, Ogris W, Korpi ER, Sieghart W, Somogyi P, Wisden W, Capogna M (2005) Loss of Zolpidem efficacy in the hippocampus of mice with the $\mathrm{GABA}_{\mathrm{A}}$ receptor gamma2 F77I point mutation. Eur J Neurosci 21:3002-3016.

Csicsvari J, Jamieson B, Wise KD, Buzsáki G (2003) Mechanisms of gamma oscillations in the hippocampus of the behaving rat. Neuron 37:311-322.

Daw MI, Ashby MC, Isaac JT (2007) Coordinated developmental recruitment of latent fast spiking interneurons in layer IV barrel cortex. Nat Neurosci 10:453-461.

Du J, Zhang L, Weiser M, Rudy B, McBain CJ (1996) Developmental expression and functional characterization of the potassium-channel subunit Kv3.1b in parvalbumin-containing interneurons of the rat hippocampus. J Neurosci 15:506-518.

Dupuy ST, Houser CR (1997) Developmental changes in GABA neurons of the rat dentate gyrus: an in situ hybridization and birthdating study. J Comp Neurol 389:402-418.

Fisahn A, Pike FG, Buhl EH, Paulsen O (1998) Cholinergic induction of network oscillations at $40 \mathrm{~Hz}$ in the hippocampus in vitro. Nature 394:186-189.

Freund TF, Buzsáki G (1996) Interneurons of the hippocampus. Hippocampus 6:347-470.

Fritschy J-M, Möhler H (1995) GABA $_{\mathrm{A}}$-receptor heterogeneity in the adult rat brain: differential regional and cellular distribution of seven major subunits. J Comp Neurol 359:154-194.

Fuchs EC, Zivkovic AR, Cunningham MO, Middleton S, LeBeau FE, Bannerman DM, Rozov A, Whittington MA, Traub RD, Rawlins JN, Monyer H (2007) Recruitment of parvalbumin-positive interneurons determines hippocampal function and associated behavior. Neuron 53:591-604.

Galarreta M, Hestrin S (2001) Spike transmission and synchrony detection in networks of GABAergic interneurons. Science 292:2295-2299.

Galarreta M, Hestrin S (2002) Electrical and chemical synapses among parvalbumin fast-spiking GABAergic interneurons in adult mouse neocortex. Proc Natl Acad Sci USA 99:12438-12443.

Geiger JRP, Lübke J, Roth A, Frotscher M, Jonas P (1997) Submillisecond AMPA receptor-mediated signaling at a principal neuron-interneuron synapse. Neuron 18:1009-1023.

Gray CM, Singer W (1989) Stimulus-specific neuronal oscillations in orientation columns of cat visual cortex. Proc Natl Acad Sci USA $86: 1698-1702$.

Hefft S, Jonas P (2005) Asynchronous GABA release generates long-lasting inhibition at a hippocampal interneuron-principal neuron synapse. Nat Neurosci 8:1319-1328.

Hensch TK (2005) Critical period plasticity in local cortical circuits. Nat Rev Neurosci 6:877-888.

Hille B (2001) Ionic channels of excitable membranes, Ed 3. Sunderland, MA: Sinauer.

Hines ML, Carnevale NT (1997) The NEURON simulation environment. Neural Comput 9:1179-1209.

Hollrigel GS, Soltesz I (1997) Slow kinetics of miniature IPSCs during early postnatal development in granule cells of the dentate gyrus. J Neurosci 17:5119-5128.

Jack JJB, Noble D, Tsien RW (1975) Electric current flow in excitable cells. Oxford: Clarendon.

Klausberger T, David J, Roberts B, Somogyi P (2002) Cell type- and inputspecific differences in the number and subtypes of synaptic $\mathrm{GABA}_{\mathrm{A}}$ receptors in the Hippocampus. J Neurosci 22:2513-2521.

Koh DS, Burnashev N, Jonas P (1995) Block of native $\mathrm{Ca}^{2+}$-permeable AMPA receptors in rat brain by intracellular polyamines generates double rectification. J Physiol (Lond) 486:305-312.

Kosaka T, Hama K (1985) Gap junctions between non-pyramidal cell dendrites in the rat hippocampus (CA1 and CA3 regions): a combined Golgielectron microscopy study. J Comp Neurol 231:150-161.

Lahtinen H, Palva JM, Sumanen S, Voipio J, Kaila K, Taira T (2002) Postnatal development of rat hippocampal Gamma rhythm in vivo. J Neurophysiol 88:1469-1474.

Laurie DJ, Wisden W, Seeburg PH (1992) The distribution of thirteen $\mathrm{GABA}_{\mathrm{A}}$ receptor subunit mRNAs in the rat brain. III. Embryonic and postnatal development. J Neurosci 12:4151-4172.

Lavoie AM, Tingey JJ, Harrison NL, Pritchett DB, Twyman RE (1997) Ac- tivation and deactivation rates of recombinant $\mathrm{GABA}_{\mathrm{A}}$ receptor channels are dependent on alpha-subunit isoform. Biophys J 73:2518-2526.

Leinekugel X, Khazipov R, Cannon R, Hirase H, Ben-Ari Y, Buzsáki G (2002) Correlated bursts of activity in the neonatal hippocampus in vivo. Science 296:2049-2052.

Long MA, Cruikshank SJ, Jutras MJ, Connors BW (2005) Abrupt maturation of a spike-synchronizing mechanism in neocortex. Neuroscience 25:7309-7316.

Martin PD, Berthoz A (2002) Development of spatial firing in the hippocampus of young rats. Hippocampus 12:465-480.

McBain CJ, Fisahn A (2001) Interneurons unbound. Nat Rev Neurosci 2:11-23.

Meyer AH, Katona I, Blatow M, Rozov A, Monyer H (2002) In vivo labeling of parvalbumin-positive interneurons and analysis of electrical coupling in identified neurons. J Neurosci 22:7055-7064.

Miles R, Tóth K, Gulyás AI, Hájos N, Freund TF (1996) Differences between somatic and dendritic inhibition in the hippocampus. Neuron $16: 815-823$.

Nusser Z, Roberts JDB, Baude A, Richards JG, Sieghart W, Somogyi P (1995) Immunocytochemical localization of the $\alpha 1$ and $\beta 2 / 3$ subunits of the $\mathrm{GABA}_{\mathrm{A}}$ receptor in relation to specific GABAergic synapses in the dentate gyrus. Eur J Neurosci 7:630-646.

Parra P, Gulyás AI, Miles R (1998) How many subtypes of inhibitory cells in the hippocampus? Neuron 20:983-993.

Penttonen M, Kamondi A, Acsády L, Buzsáki G (1998) Gamma frequency oscillation in the hippocampus of the rat: intracellular analysis in vivo. Eur J Neurosci 10:718-728.

Pouille F, Scanziani M (2001) Enforcement of temporal fidelity in pyramidal cells by somatic feed-forward inhibition. Science 293:1159-1163.

Pouille F, Scanziani M (2004) Routing of spike series by dynamic circuits in the hippocampus. Nature 429:717-723.

Ribary U, Ioannides AA, Singh KD, Hasson R, Bolton JP, Lado F, Mogilner A, Llinás R (1991) Magnetic field tomography of coherent thalamocortical 40-Hz oscillations in humans Proc Natl Acad Sci USA 88:11037-11041.

Rudy B, McBain CJ (2001) Kv3 channels: voltage-gated $\mathrm{K}^{+}$channels designed for high-frequency repetitive firing. Trends Neurosci 24:517-526.

Sik A, Penttonen M, Ylinen A, Buzsáki G (1995) Hippocampal CA1 interneurons: an in vivo intracellular labeling study. J Neurosci 15:6651-6665.

Somogyi P, Klausberger T (2005) Defined types of cortical interneurone structure space and spike timing in the hippocampus. J Physiol (Lond) 562:9-26.

Stuart GJ, Dodt H-U, Sakmann B (1993) Patch-clamp recordings from the soma and dendrites of neurons in brain slices using infrared video microscopy. Pflugers Arch 423:511-518.

Tamamaki N, Yanagawa Y, Tomioka R, Miyazaki J, Obata K, Kaneko T (2003) Green fluorescent protein expression and colocalization with calretinin, parvalbumin, and somatostatin in the GAD67-GFP knock-in mouse. J Comp Neurol 467:60-79.

Tansey EP, Chow A, Rudy B, McBain CJ (2002) Developmental expression of potassium-channel subunit Kv3.2 within subpopulations of mouse hippocampal inhibitory interneurons. Hippocampus 12:137-148.

Taschenberger H, von Gersdorff HH (2000) Fine-tuning an auditory synapse for speed and fidelity: developmental changes in presynaptic waveform, EPSC kinetics, and synaptic plasticity. J Neurosci 20:9162-9173.

Taverna S, Tkatch T, Metz AE, Martina M (2005) Differential expression of TASK channels between horizontal interneurons and pyramidal cells of rat hippocampus. J Neurosci 25:9162-9170.

Thomson AM, Bannister AP, Hughes DI, Pawelzik H (2000) Differential sensitivity to Zolpidem of IPSPs activated by morphologically identified CA1 interneurons in slices of rat hippocampus. Eur J Neurosci 12:425-436.

Torborg CL, Berg AP, Jeffries BW, Bayliss DA, McBain CJ (2006) TASK-like conductances are present within hippocampal CA1 stratum oriens interneuron subpopulations. J Neurosci 26:7362-7367.

Towers SK, LeBeau FE, Gloveli T, Traub RD, Whittington MA, Buhl EH (2002) Fast network oscillations in the rat dentate gyrus in vitro. J Neurophysiol 87:1165-1168.

Traub RD, Whittington MA, Colling SB, Buzsáki G, Jefferys JG (1996) Analysis of gamma rhythms in the rat hippocampus in vitro and in vivo. J Physiol (Lond) 493:471-484.

Traub RD, Bibbig A, LeBeau FE, Buhl EH, Whittington MA (2004) Cellular 
mechanisms of neuronal population oscillations in the hippocampus in vitro. Annu Rev Neurosci 27:247-278.

Tyzio R, Represa A, Jorquera I, Ben-Ari Y, Gozlan H, Aniksztejn L (1999) The establishment of GABAergic and glutamatergic synapses on CA1 pyramidal neurons is sequential and correlates with the development of the apical dendrite. J Neurosci 23:10372-10382.

Vida I, Bartos M, Jonas P (2006) Shunting inhibition improves robustness of gamma oscillations in hippocampal interneuron networks by homogenizing firing rates. Neuron 49:107-117.

Wang X-J, Buzsáki G (1996) Gamma oscillation by synaptic inhibition in a hippocampal interneuronal network model. J Neurosci 16:6402-6413.
Whittington MA, Traub RD, Jefferys JGR (1995) Synchronized oscillations in interneuron networks driven by metabotropic glutamate receptor activation. Nature 373:612-615.

Williams SR, Buhl EH, Mody I (1998) The dynamics of synchronized neurotransmitter release determined from compound spontaneous IPSCs in rat dentate granule neurons in vitro. J Physiol (Lond) 510:477-497.

Yang Y-M, Wang L-Y (2006) Amplitude and kinetics of action potentialevoked $\mathrm{Ca}^{2+}$ current and its efficacy in triggering transmitter release at the developing calyx of Held synapse. J Neurosci 26:5698-5708.

Yurgelun-Todd D (2007) Emotional and cognitive changes during adolescence. Curr Opin Neurobiol 17:251-257. 